\title{
Intravenous Ferric Carboxymaltose in Patients with Type 2 Diabetes Mellitus and Iron Deficiency: CLEVER Trial Study Design and Protocol
}

\author{
Christoph Schindler - Andreas L. Birkenfeld · Markolf Hanefeld • \\ Ulrike Schatz · Carsta Köhler · Martin Grüneberg · Diethelm Tschöpe • \\ Matthias Blüher · Christoph Hasslacher · Stefan R. Bornstein
}

Received: October 11, 2017 / Published online: November 13, 2017

(C) The Author(s) 2017. This article is an open access publication

\section{ABSTRACT}

Introduction: $\mathrm{HbA1c}$ is the gold standard for glycemic control in pre-diabetes and diabetes. However, its validity has been questioned, especially in the presence of imbalanced iron homeostasis. The CLEVER trial aims to evaluate the relationship between iron deficiency and HbA1c (a biomarker for the diagnosis and therapeutic monitoring of type 2 diabetes) in a randomized, placebo-controlled, multicenter clinical trial.

Methods: The CLEVER (intravenous ferric CarboxymaLtosE for improVement of mEtabolic parameters in type 2 diabetes patients with iRon

Enhanced Content To view enhanced content for this article go to https://www.medengine.com/Redeem/ 8DCCF06025616539.

C. Schindler $(\bowtie)$

Clinical Research Center Hannover and Center for Pharmacology and Toxicology, Hannover Medical School, Hannover, Germany

e-mail: schindler.christoph@mh-hannover.de

A. L. Birkenfeld · U. Schatz · S. R. Bornstein Medical Clinic and Policlinic III at the University Hospital Dresden, Dresden, Germany

\section{A. L. Birkenfeld · M. Hanefeld}

Centre for Metabolic Vascular Medicine, GWT-TUD, Dresden, Germany

C. Köhler

Medical Consulting, GWT-TUD, Dresden, Germany deficiency) trial is a randomized, single-blind, proof-of-concept study with two treatment arms. 140 men and women diagnosed with type 2 diabetes and iron deficiency will receive either placebo or ferric carboxymaltose $(500$ or $1000 \mathrm{mg}$ ) as intravenous infusions. The primary outcome measure is the change in HbA1c level between baseline and after 12 weeks of treatment. Secondary endpoints include change of iron status and metabolic markers as well as treatment safety and tolerability. Furthermore, the potential clinical improvement in quality of life and the reliability of HbA1c measurement in patients with type 2 diabetes and iron deficiency will be investigated.

Results: Both excessive iron and iron deficiency are associated with metabolic disorders; excessive iron is a risk factor for the development of diabetes, whereas iron deficiency is associated

\author{
M. Grüneberg \\ Diabetes Center Herne, Herne, Germany \\ D. Tschöpe \\ Herz- und Diabeteszentrum Nordrhein-Westfalen, \\ Ruhr-Universität Bochum, Bad Oeynhausen, \\ Germany \\ M. Blüher \\ Department of Medicine at the University Hospital \\ Leipzig, Leipzig, Germany \\ C. Hasslacher \\ Diabetesinstitut Heidelberg and Department of \\ Clinical Studies, St. Josefskrankenhaus Heidelberg, \\ Heidelberg, Germany
}


with obesity and insulin resistance. It has been suggested that iron increases insulin secretion in pancreatic beta-cells. CLEVER is the first study to investigate the hypothesis that intravenous substitution with ferric carboxymaltose reduces HbA1c levels in patients with type 2 diabetes and iron deficiency, thereby improving metabolic status and quality of life.

Clinical Trial Registration: ClinicalTrials.gov (NCT01513369).

Funding: GWT-TUD GmbH acts as sponsor of the clinical trial. Financial support is provided by Vifor Pharma.

Keywords: Ferinject ${ }^{\circledR}$; Ferric carboxymaltose; HbA1c; Intravenous; Iron deficiency; Type 2 diabetes mellitus

\section{INTRODUCTION}

Iron influences glucose metabolism, and the link between iron metabolism and diabetes is well established $[1,2]$. The relationship is bidirectional: iron affects glucose metabolism, and glucose metabolism interferes with several iron metabolic pathways. Whereas excessive iron seems to be involved in the pathogenesis of diabetes, iron deficiency has been linked with obesity and insulin resistance. However, the crosstalk between iron and energy metabolism as well as pathophysiological processes such as inflammation, peripheral ischemia, and hypoxia is still not fully understood [3].

Although the HbA1c value is well established as a biomarker for the diagnosis of diabetes and for monitoring the treatment of diabetes, its reliability, especially under conditions of an altered iron homeostasis, has been challenged. HbA1c levels appear to be affected by iron status, as several studies have demonstrated increased values under conditions of iron depletion and iron deficiency anemia (IDA) in both type 1 diabetic and nondiabetic populations [4-7]. On the other hand, iron substitution therapy results in a significant drop in HbA1c values [5-7]. There is evidence that iron-associated elevations and reductions in HbA1c do not properly reflect glycemic status, resulting in a spuriously exaggerated number of people that are diagnosed with pre-diabetes and diabetes and overtreatment when HbA1c is used as the primary indicator for glycemic control [8-10].

The hypothesis to be tested in the CLEVER trial is that infusion of ferric carboxymaltose (FCM) in patients with type 2 diabetes (T2DM) and iron deficiency (ID) significantly reduces HbA1c, as has already been shown for other populations, e.g., nondiabetic people and patients with type 1 diabetes. The reliability of HbA1c as an indicator for glycemic control will be assessed by the concomitant determination of fasting blood glucose and fructosamine. Moreover, the treatment of ID and metabolic status improvement are expected to have an impact on the overall quality of life, which will be evaluated as a secondary endpoint.

\section{METHODS}

\section{Study Design}

The CLEVER trial is designed as a multicenter, randomized, single-blind, proof-of-concept study. Men and women with T2DM and ID are randomized $1: 1$ to treatment with either FCM or placebo ( $0.9 \% \mathrm{NaCl}$ solution) administered as an intravenous drip infusion over $30 \mathrm{~min}$. The aim of the study is to investigate a systematic influence of ID on HbA1c. Participants will also be monitored for the occurrence of treatment-emergent adverse events and overall health status. After confirming eligibility at the screening visit (V1a), participants will enter the treatment phase, consisting of three visits. At visit $1 \mathrm{~b}$, baseline data for iron and metabolic status and quality of life will be recorded, and the first dose of the study medication will be administered. FCM (Ferinject ${ }^{\circledR}$, Vifor Pharma Deutschland $\mathrm{GmbH}$ ) will be dosed at 500 or $1000 \mathrm{mg}$, depending on the individual body weight and hemoglobin level (Fig. 1). This will be followed by an observation period of $30 \mathrm{~min}$ to monitor the tolerability of the infusion. Iron status will be assessed based on the following laboratory parameters: ferritin, transferrin, transferrin saturation (TSAT), soluble transferrin receptor (sTFR), serum iron, hemoglobin, mean 
corpuscular volume, mean corpuscular hemoglobin, \% hypochromic cells, reticulocyte hemoglobin content, and hepcidin. HbA1c, fasting blood glucose, and fructosamine as well as the insulin dosage used will serve as markers to assess the metabolic status. Overall health status and quality of life (QoL) will be evaluated by the Euro-QoL (EQ5D) questionnaire. In accordance with the summary of product characteristics (SmPC) and the study protocol, participants will receive a second dose of study medication at visit $2 \mathrm{a}$, which is scheduled for 4 weeks after the first dose. In cases where iron deficiency persists, a third dose will be administered approximately 5 days after the second dosing (visit $2 b$ ). Finally, primary and secondary outcome parameters will be assessed at the end-of-study visit scheduled for 8 weeks after the application of the final dose of study medication. The visit schedule, including study-related actions/measures, is shown in Table 1.

This trial is registered under the US National Institutes of Health ClinicalTrials.gov identifier NCT01513369. All procedures followed were in accordance with the ethical standards of the responsible committee on human experimentation (institutional and national) and with the Helsinki Declaration of 1964, as revised in 2013. Informed consent was obtained from all patients for being included in the study.

\section{Study Population}

Men and women 18 years or older and diagnosed with T2DM as well as ID (defined as serum ferritin $<150 \mathrm{ng} / \mathrm{mL}$ or transferrin saturation $<25 \%$ if hemoglobin $<14 \mathrm{~g} / \mathrm{dL}$; or serum ferritin $<100 \mathrm{ng} / \mathrm{mL}$ or transferrin saturation $<20 \%$ if hemoglobin $\geq 14 \mathrm{~g} / \mathrm{dL}$ and $\leq 15 \mathrm{~g} /$ $\mathrm{dL})$ are eligible for inclusion in the CLEVER trial. HbA1c values between 48 and $69 \mathrm{mmol} / \mathrm{mol} \mathrm{(6.5 \%}$ and 8.5\%) were defined for inclusion in the study based on data from El-Agouza et al. [7], who showed that HbA1c values of nondiabetic people treated with iron were reduced from $6.15 \% \pm 0.62 \%$ to $5.25 \% \pm 0.45 \%$. Consequently, it was hypothesized that people with T2DM will demonstrate a

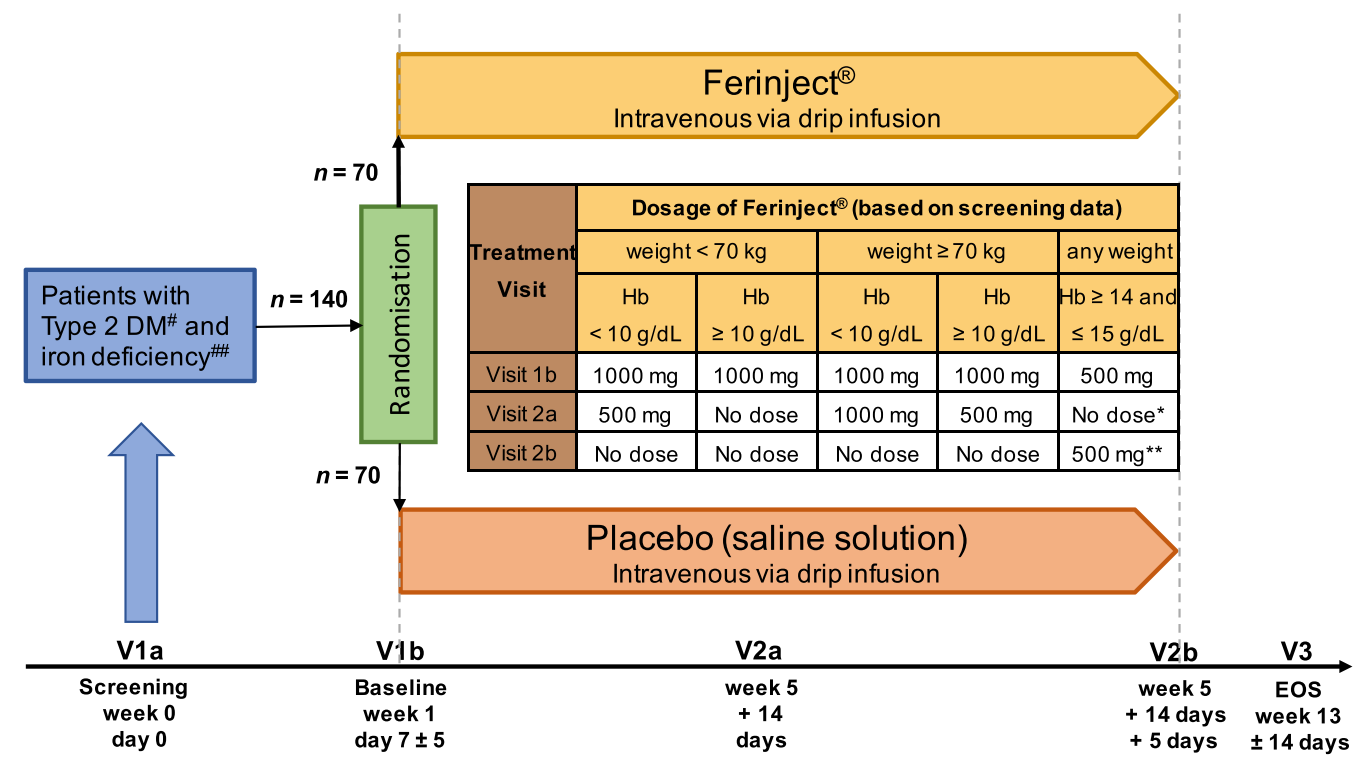

Fig. 1 CLEVER study design. "Defined as $\mathrm{HbAlc} \geq 48 \mathrm{mmol} / \mathrm{mol} \quad(6.5 \%)$ and $<69 \mathrm{mmol} / \mathrm{mol}$ (8.5\%). \#\# Defined as serum ferritin $<150 \mathrm{ng} / \mathrm{mL}$ or transferrin saturation $<25 \%$ if hemoglobin $<14 \mathrm{~g} / \mathrm{dL}$ or serum ferritin $<100 \mathrm{ng} / \mathrm{mL}$ or transferrin saturation $<20 \%$ if hemoglobin $\geq 14 \mathrm{~g} / \mathrm{dL}$ and $\leq 15 \mathrm{~g} / \mathrm{dL}$.
${ }^{*}$ Control parameter: ferritin and transferrin saturation. **If still iron deficient at V2a [serum ferritin $<150 \mathrm{ng} / \mathrm{mL}$ or transferrin saturation $<25 \%]$, an additional dose of $500 \mathrm{mg}$ ferric carboxymaltose is given at V2b, otherwise it is not 
Table 1 Visit schedule and study-related actions/measures

\begin{tabular}{|c|c|c|c|c|c|}
\hline Visit & $\begin{array}{l}\text { 1a } \\
\text { Week } 0 \\
\text { Day } 0 \\
\text { Screening }\end{array}$ & $\begin{array}{l}1 \mathbf{b} \\
\text { Week } 1 \\
\text { Day } 7 \pm \\
5 \text { days } \\
\text { Baseline }\end{array}$ & $\begin{array}{l}2 \mathrm{a} \\
\text { Week } 5 \\
\pm 14 \text { days }\end{array}$ & $\begin{array}{l}(2 b)^{*} \\
\text { Week } 5 \\
\pm 14 \text { days } \\
+5 \text { days }\end{array}$ & $\begin{array}{l}3 \\
\text { Week } 13 \\
\pm 14 \text { days } \\
\text { End of study }\end{array}$ \\
\hline Informed consent & $\boldsymbol{\nu}$ & & & & \\
\hline Inclusion/exclusion criteria & $\checkmark$ & & & & \\
\hline Demographic data & $\boldsymbol{V}$ & & & & \\
\hline Height, weight, BMI, waist circumference & $\boldsymbol{\nu}$ & & & & \\
\hline Anamnesis/medical history & $\boldsymbol{V}$ & & & & \\
\hline Urine pregnancy test & $\checkmark$ & & & & \\
\hline Concomitant medication & $\boldsymbol{V}$ & $\checkmark$ & $\checkmark$ & $(\boldsymbol{V})$ & $\checkmark$ \\
\hline Randomization & & $\checkmark$ & & & \\
\hline Vital signs (blood pressure, pulse, body temperature) & $\checkmark$ & $\checkmark$ & $\boldsymbol{V}$ & $(\boldsymbol{V})$ & $\boldsymbol{V}$ \\
\hline Laboratory & $\checkmark$ & & $\checkmark$ & & $\checkmark$ \\
\hline Study drug administration & & $\checkmark$ & $\boldsymbol{\nu}$ & $(\boldsymbol{V})$ & \\
\hline Adverse event and serious adverse event & & $\checkmark$ & $\boldsymbol{V}$ & $(\boldsymbol{V})$ & $\checkmark$ \\
\hline Documentation of used insulin and blood glucose & & $\checkmark$ & $\checkmark$ & & $\boldsymbol{V}$ \\
\hline Euro-QoL (EQ5D) questionnaire & & $\checkmark$ & $\checkmark$ & & $\boldsymbol{V}$ \\
\hline
\end{tabular}

* If still iron deficient [serum ferritin $<150 \mathrm{ng} / \mathrm{mL}$ or ferritin saturation $<25 \%$ ], an additional visit (visit $2 \mathrm{~b}$ ) for administration of $500 \mathrm{mg}$ ferric carboxymaltose is necessary, otherwise it is not

similar response. A detailed list of inclusion and exclusion criteria is given in Table 2.

The protocol will be conducted in accordance with the Declaration of Helsinki and good clinical practice guidelines and approved by each center's institutional ethics review board. Informed consent for inclusion in the study will be obtained from all patients.

\section{Study Objectives}

The primary aim of the study is to confirm that HbA1c levels are reduced after iron repletion therapy in people with ID and T2DM, as has already been reported for different populations such as healthy subjects, pregnant women, or patients with type 1 diabetes [5, 6, 11]. Moreover, the interrelationships of iron treatment and the subsequent reduction in HbA1c with selected parameters of overall health status and glucose metabolism will be assessed in more detail. For this purpose, changes in primary and secondary endpoints between baseline and 12 weeks after the start of intravenous iron repletion therapy will be evaluated. A full list of primary and secondary endpoints is presented in Table 3.

\section{Sample Size Calculation}

The study will be conducted as a single-blind, randomized, controlled, hypothesis-generating pilot study. Originally, a systematic statistical case number calculation was performed. The estimated reduction in HbA1c due to iron substitution in type 1 diabetes patients reported in the published literature is $-2.3 \%$ [5]. Calculating with a power of $80 \%$, an alpha of 0.05 , and 
Table 2 Key inclusion and exclusion criteria

\begin{tabular}{|c|c|}
\hline \multirow{5}{*}{$\begin{array}{l}\text { Key inclusion } \\
\text { criteria }\end{array}$} & Men and women older than 18 years \\
\hline & Diagnosis of type 2 diabetes and iron deficiency defined as follows: \\
\hline & $\mathrm{HbAlc} \geq 48 \mathrm{mmol} / \mathrm{mol}(6.5 \%)$ and $<69 \mathrm{mmol} / \mathrm{mol}(8.5 \%)$ \\
\hline & Serum ferritin $<150 \mathrm{ng} / \mathrm{mL}$ or transferrin saturation $<25 \%$ if hemoglobin $<14 \mathrm{~g} / \mathrm{dL}$ \\
\hline & Serum ferritin $<100 \mathrm{ng} / \mathrm{mL}$ or transferrin saturation $<20 \%$ if hemoglobin $\geq 14 \mathrm{~g} / \mathrm{dL}$ and $\leq 15 \mathrm{~g} / \mathrm{dL}$ \\
\hline \multirow{18}{*}{$\begin{array}{l}\text { Key exclusion } \\
\text { criteria }\end{array}$} & Continuous subcutaneous insulin infusion \\
\hline & Thalassemia \\
\hline & Hemoglobin $>15 \mathrm{~g} / \mathrm{dL}(\geq 9.31 \mathrm{mmol} / \mathrm{L})$ \\
\hline & C-reactive protein $>15 \mathrm{mg} / \mathrm{L}$ \\
\hline & Change in $\mathrm{HbAlc}$ of more than $\pm 0.3 \%$ within the last 3 months \\
\hline & Hypersensitivity to the active substance, to Ferinject, or to any of its excipients \\
\hline & Known serious hypersensitivity to other parenteral iron products \\
\hline & History of acquired iron overload \\
\hline & $\begin{array}{l}\text { History of erythropoietin-stimulating agent, IV or high-dose oral iron therapy or blood } \\
\text { transfusion }<12 \text { weeks prior to randomization }\end{array}$ \\
\hline & Body weight $\leq 40 \mathrm{~kg}$ \\
\hline & Chronic or active liver disease \\
\hline & Vitamin B12 and/or serum folate deficiency \\
\hline & Current malignancy under treatment \\
\hline & Renal function GFR $<30 \mathrm{~mL} / \mathrm{min} / 1.73 \mathrm{~m}^{2}$ \\
\hline & Significant major cardiovascular disease ongoing or in the past 3 months \\
\hline & Polyneuropathy without ischemia \\
\hline & Pregnant or nursing (lactating) women \\
\hline & $\begin{array}{l}\text { Any person not willing to use adequate contraceptive precautions during the study and for up to } 5 \text { days } \\
\text { after the last scheduled dose of study medication }\end{array}$ \\
\hline
\end{tabular}

an expected HbA1c difference due to intravenous iron substitution in the present study of $0.7 \% \pm 1.4 \%$, a total of $n=126$ participants (63 per treatment arm) must be included in the CLEVER trial in order to reach statistical significance. Assuming a 20\% expected dropout rate, this sample size would need to be increased to 152 participants, i.e., 76 per treatment group. However, if the dropout rate is only $10 \%, 70$ patients per treatment arm will be sufficient to reach statistical significance. An interim analysis is planned in order to re-evaluate the validity of the hypothesis for the HbA1c difference between the two treatment arms after 64 patients (32 patients per arm) have completed the study. This interim analysis will follow the three zones method described by Mehta and Pocock [12] using the Lan-DeMets procedure and an O'Brien-Fleming spending function. The final number of participants to be included will be adjusted during the study depending on the dropout rate and results from the interim analysis. 
Table 3 Study endpoints

$\begin{gathered}\text { Change in HbAlc from baseline to the } \\ \text { endpoint } \\ \text { end of the study } \\ \text { endpoints }\end{gathered}$
Change in iron status from baseline to
the end of the study as measured by
hemoglobin, mean corpuscular volume,
mean corpuscular hemoglobin, \%
hypochromic cells, reticulocyte
hemoglobin content, ferritin,
transferrin, transferrin saturation
(TSAT), soluble transferrin receptor
(sTFR), serum iron, hepcidin
Change in metabolic status from baseline
to the end of the study as measured by
fasting blood glucose and fructosamine
Change in insulin dosage used per
application from baseline to the end of
the study
Reliability of HbAlc measurements
Change in quality of life from baseline to
the end of treatment as assessed by
Euro-QoL (EQ5D) questionnaire

\section{Statistical Methods}

Continuous variables will be checked for normality using the Kolmogorov-Smirnov test, and non-normally distributed variables will be log-transformed before analysis. If no normal distribution is obtained, the Mann-Whitney $U$ test will be used instead of a $t$ test. A summary of baseline data (demographic, anamnestic data, and laboratory parameters) will be provided. The compilation will involve a comparison of mean values, indicating the corresponding standard deviations, as well as $t$ tests between the treatment arms. For nominal variables, the frequency will be counted and tested using the chi-square test to check for significant differences between treatment groups.

Changes in primary and secondary parameters between baseline and the end of the study will be tested using a paired $t$ test or a Wilcoxon rank sum test for each treatment arm and using an independent $t$ test for the last visit between treatment arms. A boxplot or confidence interval plot will be presented. If the baseline values of HbA1c are significantly different between the treatment groups, an analysis of covariance (ANCOVA) for HbA1c at the last visit will be needed. A linear model will be searched for using stepwise regression (forward and backward selection) with all independent variables at the beginning of the selection.

All nominal and categorical variables will be summarized descriptively with the following parameters: number of observations and absolute and relative frequencies based on the number of observations. Continuous and ordinal variables will be summarized by means of number of observations, arithmetic mean, standard deviation, median, p5, p25, p75, and p95 percentiles, and the minimum and maximum. Correlations will be calculated using Pearson correlation coefficients.

The statistical analysis of primary and secondary endpoints will be done on the per-protocol set, which includes all participants who are randomized and treated according to the protocol. Safety parameters will be listed for all participants who received at least one dose of study medication.

\section{DISCUSSION}

Roughly one-third of the general population is affected by ID, which is one of the most common nutritional deficiencies worldwide [13]. ID designates a reduction in storage iron (as shown by reduced serum ferritin and confirmed by decreased bone marrow iron staining) as well as decreased utilizable iron (represented by reduced transferrin saturation values), which indicates the amount of immediately available iron. Several chronic disorders such as rheumatic disease, metabolic syndrome, coronary artery disease, and chronic liver disease are confounded by alterations in iron homeostasis [14-17], and correcting ID may impact morbidity, mortality, and quality of life in these patients. Iron deficiency anemia (IDA) is a 
Table 4 Studies demonstrating a decrease in $\mathrm{HbAlc}$ after iron substitution therapy (HbAlc values are given as mean \pm SD or $[95 \%$ confidence interval])

\begin{tabular}{|c|c|c|c|c|c|c|}
\hline Reference & Population & $n$ & $\begin{array}{l}\text { HbAlc before } \\
\text { treatment }\end{array}$ & $\begin{array}{l}\text { HbAlc after } \\
\text { treatment }\end{array}$ & $\begin{array}{l}\text { Difference in } \\
\text { mean HbAlc }\end{array}$ & Treatment \\
\hline $\begin{array}{l}\text { Davis } \\
1983 \\
{[30]}\end{array}$ & $\begin{array}{l}\text { 68-year-old woman } \\
\text { with IDA and DM }\end{array}$ & 1 & $\begin{array}{l}\text { 10.7\% (without } \\
\quad \text { IDA) } \\
15.4 \% \\
\text { (with IDA) }\end{array}$ & $11 \%$ & $4.4 \%$ & Not disclosed \\
\hline $\begin{array}{l}\text { Tarim } \\
1999 \text { [5] }\end{array}$ & $\begin{array}{l}\text { Patients with type } 1 \\
\text { DM and ID }\end{array}$ & 11 & $10.6 \% \pm 2.6 \%$ & $8.3 \% \pm 2.6 \%$ & $\begin{array}{l}2.3 \% \\
\quad(P<0.05)\end{array}$ & $\begin{array}{l}\text { Oral } 6 \mathrm{mg} / \mathrm{kg} / \text { day for } \\
3 \text { months }\end{array}$ \\
\hline $\begin{array}{l}\text { Tarim } \\
1999[5]\end{array}$ & $\begin{array}{l}\text { Nondiabetic patients } \\
\text { with ID }\end{array}$ & 11 & $7.7 \% \pm 1.3 \%$ & $6.4 \% \pm 1.2 \%$ & $\begin{array}{l}1.3 \% \\
\quad(P<0.05)\end{array}$ & $\begin{array}{l}\text { Oral } 6 \mathrm{mg} / \mathrm{kg} / \text { day for } \\
3 \text { months }\end{array}$ \\
\hline $\begin{array}{l}\text { El-Agouza } \\
2002[7]\end{array}$ & Students with IDA & 51 & $6.15 \% \pm 0.62 \%$ & $5.25 \% \pm 0.45 \%$ & $\begin{array}{l}0.9 \% \\
\quad(P<0.001)\end{array}$ & $\begin{array}{l}\text { Oral ferrous sulphate } \\
325 \mathrm{mg} / \text { day for } 20 \text { weeks }\end{array}$ \\
\hline $\begin{array}{l}\text { Coban } \\
2004[6]\end{array}$ & $\begin{array}{l}\text { Nondiabetic patients } \\
\text { with IDA }\end{array}$ & 50 & $7.4 \% \pm 0.8 \%$ & $6.2 \% \pm 0.6 \%$ & $\begin{array}{l}1.2 \% \\
\quad(P<0.001)\end{array}$ & $\begin{array}{l}\text { Oral } 100 \mathrm{mg} / \text { day for } \\
3 \text { months }\end{array}$ \\
\hline $\begin{array}{c}\mathrm{Ng} 2010 \\
{[22]}\end{array}$ & $\begin{array}{l}\text { Patients with type } 2 \\
\text { DM and chronic } \\
\text { kidney disease }\end{array}$ & 15 & $\begin{array}{l}7.40 \% \\
{[6.60-8.19]}\end{array}$ & $\begin{array}{l}6.96 \% \\
{[6.27-7.25]}\end{array}$ & $\begin{array}{l}0.4 \% \\
\quad(P<0.001)\end{array}$ & $\begin{array}{l}\text { Single dose of low } \\
\text { molecular weight iron } \\
\text { dextran as IV infusion }\end{array}$ \\
\hline
\end{tabular}

global public health burden and appears to be more common in people with diabetes than in the nondiabetic population. IDA negatively affects glycemic control. Thus, correcting IDA can be expected to improve diabetes control and prevent disease-related complications [18].

The bidirectional relationship between iron metabolism and glucose homeostasis is increasingly being recognized. A relative iron excess appears to affect metabolic processes such as insulin action and secretion. Consequently, ensuring balanced body iron stores may be a promising therapeutic target for people suffering from T2DM as well as for those at risk of developing T2DM [2]. In a population of 883 subjects with no known history of diabetes, Shimodaira et al. [19] demonstrated that serum iron levels were not associated with insulin resistance or $\beta$-cell function. However, it was speculated that insulin secretion was negatively affected by higher hemoglobin levels.

HbA1c, the major form of glycated hemoglobin, was incorporated into a monitoring program for individuals with diabetes in 1976, and is now the gold standard for glycemic control. In healthy people, HbA1c reaches a steady state at $3.0 \%-6.5 \%(9-48 \mathrm{mmol} / \mathrm{mol})$ of the overall body hemoglobin, while the HbA1c fraction is abnormally elevated in patients with chronic hyperglycemia and is positively correlated with glycemic control. However, certain conditions such as genetic variants that alter HbA1c through nonglycemic pathways may affect its validity as marker for glycemic control [20]. Furthermore, the reliability of HbA1c as a biomarker for the diagnosis of diabetes and for monitoring treatment in patients with diabetes suffering from imbalanced iron homeostasis is being questioned, as iron depletion spuriously increases HbA1c values-there is no corresponding change in blood glucose [10]. Rajagopal [4] as well as Silva [21] and coworkers demonstrated a statistically significant difference in HbA1c values between cases of mild, moderate, and severe IDA, even in nondiabetic individuals. On the other hand, a significant drop in HbA1c with iron substitution therapy has been observed in various populations, including people with no history of diabetes and people with type 1 diabetes (see Table 4 ). 
Notably, the only study that investigated the effect of iron supplementation in a population with T2DM included patients who additionally suffered from chronic kidney disease. As such, this study was also able to demonstrate that intravenous iron caused a significant decrease in HbA1c values without any change in glycemic control in patients who primarily had T2DM and ID [22].

In the literature, several hypotheses for the increase in HbA1c under iron-depleted conditions have been discussed. Brooks et al. [23] proposed that the quaternary structure of the hemoglobin molecule is altered in ID, which may result in more rapid glycosylation of the $\beta$ chain. Other scientists have argued that conditions affecting erythrocyte turnover may also influence HbA1c concentrations, and have suggested that the rise in $\mathrm{HbA} 1 \mathrm{c}$ may be a result of reduced cell production in IDA, leading to an extended lifespan of circulating erythrocytes [24]. Studies by El-Agouza et al. [7] and Coban et al. [6] demonstrated elevated levels of HbA1c in IDA patients which significantly decreased after iron substitution therapy. They postulated that under conditions of IDA, the decreased hemoglobin concentration would result in an increased glycated fraction if the serum glucose remained constant.

Interestingly, a series of other studies investigating the effect of IDA on HbA1c draw a contradictory picture, as they revealed a decreased HbA1c at baseline and a subsequent rise with iron supplementation, or no difference between IDA and nonanemic populations [25-27].

Although this topic has been addressed by many groups within the last decade, and a couple of hypotheses have been proposed, there is still no sufficiently proven explanation that supports any of these hypotheses in particular, and so further studies are warranted to shed more light on the relationship between ID and HbA1c. However, there is a general consensus that abnormalities in erythrocyte indices are a considerable confounder in the analysis of $\mathrm{HbA1c}$, and there is currently insufficient data to guide physicians in everyday clinical practice. Therefore, English et al. [28] elaborated a couple of recommendations to consider in addition to the published guidance. For the time being, implementing these rules would prevent the misdiagnosis of diabetes in people with ID who are in the threshold range of HbA1c, as well as the overtreatment of well-adjusted people with diabetes who develop ID and would, in the worst case scenario, end up with a high risk of hypoglycemia.

The investigator-initiated CLEVER trial is designed to evaluate if people with T2DM profit from intravenous iron therapy with FCM. Recently, HbA1c > $7.5 \%(48 \mathrm{mmol} / \mathrm{mol})$ has been introduced as the cutoff limit for newly diagnosed diabetes. This level of HbA1c control is recommended by national and international guidelines. Thus, falsely high measured levels of HbA1c due to ID would lead to overtreatment, with potentially high risks of hypoglycemia and weight gain in known diabetics who receive insulin treatment. This underscores that valid HbA1c values are particularly important in people under strict glucose control. Correcting ID is presumed to improve glucose status in these patients and may additionally have a positive clinical impact on vascular function in patients with T2DM on oral antidiabetic combination therapy. Many people with diabetes already have an impaired quality of life and ID constitutes an additional burden. A reduced hemoglobin level also identifies diabetics who are at an increased risk of adverse outcomes, independent of the presence or severity of nephropathy.

In the present study, reconstitution or at least an improvement in iron homeostasis will be achieved by intravenous infusion of FCM, which has greater bioavailability and compliance and was demonstrated to be more effective and (due to its lack of gastrointestinal intolerance) better tolerated than oral iron [29]. Thus, the study will also provide important data about the pharmacodynamics of ferric carboxymaltose and address the question of whether data attained after intravenous iron substitution therapy are comparable to those obtained after oral dosing, as well as checking the timeframe required to achieve a clinically measurable improvement. A series of parameters for the characterization of easily available iron and iron stores will be evaluated along with parameters 
of glycemic status. HbA1c will serve as the primary endpoint, in line with many clinical studies that investigate the effects of new medications as potential novel treatments for diabetes. However, other markers for glycemic control, such as fasting blood glucose, fructosamine, and administered insulin dosage, will be determined along with HbA1c concentrations to prove the reliability of this indicator. Furthermore, treatment-emergent adverse events and the quality of life of each study participant will be monitored. Finally, the clinical results obtained from the CLEVER trial will provide further scientific insight into the relationship between iron and metabolic status as well as its clinical relevance.

\section{CONCLUSION}

The aim of the CLEVER trial is to further investigate the link between ID, intravenous iron substitution, and HbA1c (the most clinically relevant biomarker used for diagnosing and treating type 2 diabetes as a widespread disease). It is hypothesized that intravenous substitution with FCM significantly reduces HbA1c in people with ID and T2DM, thereby improving metabolic status and quality of life. Conversely, this would mean that people suffering from ID might be misdiagnosed with diabetes. Moreover, if a diagnosis of T2DM has already been made and therapeutic control is achieved by relying on HbA1c values, patients suffering from ID are potentially overtreated, leading to a significant risk of hypoglycemic episodes. Consequently, the role of $\mathrm{HbA1c}$ as a biomarker for diagnosing and treating diabetes would likely need to be reconsidered, and changes in/restrictions on the interpretation of HbA1c values in ID patients would have to be implemented in national and international diabetes guidelines.

The results of the CLEVER trial will presumably support the use of intravenous FCM in clinical practice, especially in people suffering from diabetes and ID. As HbA1c evaluation is a cornerstone of diabetes management, it is also necessary from a drug safety point of view to critically demonstrate the validity of HbA1c as the most important clinical biomarker for monitoring diabetes therapy by performing a randomized, controlled study of a population suffering from T2DM during drug therapy with FCM, which has been shown to significantly influence and bias this parameter.

\section{ACKNOWLEDGEMENTS}

GWT-TUD GmbH acts as the sponsor for this study. The study is financially supported by Vifor Pharma Intl. AG. Sponsorship for article processing charges was also provided by Vifor Pharma Intl. AG. The authors of the publication are fully responsible for its contents and conclusions. All authors had full access to all of the data in this study and take complete responsibility for the integrity of the data and the accuracy of the data analysis. All named authors meet the International Committee of Medical Journal Editors (ICMJE) criteria for authorship for this manuscript, take responsibility for the integrity of the work as a whole, and have given their final approval of the version to be published. Editorial assistance in the preparation of this manuscript was provided by Dr. Antje Gasparic, an independent medical writer. Support for this assistance was funded by Vifor Pharma Intl. AG. The rationale and design of the CLEVER trial were also presented at the DDG 11th Diabetes Autumn Congress, Mannheim, Germany, 2017. We would like to thank all patients, their families, the investigators, and the study staff who participate in this trial.

Disclosures. Andreas L. Birkenfeld, Markolf Hanefeld, Ulrike Schatz, Carsta Köhler, Martin Grüneberg, Diethelm Tschöpe, Christoph Hasslacher, and Stefan R. Bornstein have nothing to disclose.

Christoph Schindler has received honoraria for lectures and advisory board participations from Boehringer Ingelheim and AstraZeneca. Matthias Blüher has received honoraria for invited lectures and advisory board participations from AstraZeneca, Boehringer Ingelheim, Eli Lilly, Novo Nordisk, Novartis, and Sanofi. 
Compliance with Ethics Guidelines. All procedures followed are in accordance with the ethical standards of the responsible committees on human experimentation (institutional and national) and with the Helsinki Declaration of 1964, as revised in 2013. Informed consent for inclusion in the study will be obtained from all patients.

Open Access. This article is distributed under the terms of the Creative Commons Attribution-NonCommercial 4.0 International License (http://creativecommons.org/licenses/ by-nc/4.0/), which permits any noncommercial use, distribution, and reproduction in any medium, provided you give appropriate credit to the original author(s) and the source, provide a link to the Creative Commons license, and indicate if changes were made.

\section{REFERENCES}

1. Fernandez-Real JM, Lopez-Bermejo A, Ricart W. Cross-talk between iron metabolism and diabetes. Diabetes. 2002;51(8):2348-54.

2. Fernandez-Real JM, McClain D, Manco M. Mechanisms linking glucose homeostasis and iron metabolism toward the onset and progression of type 2 diabetes. Diabetes Care. 2015;38(11):2169-76.

3. Wang X, Fang X, Wang F. Pleiotropic actions of iron balance in diabetes mellitus. Rev Endocr Metab Disord. 2015;16(1):15-23.

4. Rajagopal L, Ganapathy S, Arunachalam S, Raja V, Ramraj B. Does iron deficiency anaemia and its severity influence HbA1C level in non diabetics? An analysis of 150 cases. J Clin Diagn Res. 2017;11(2):E13-5.

5. Tarim O, Kucukerdogan A, Gunay U, Eralp O, Ercan I. Effects of iron deficiency anemia on hemoglobin A1c in type 1 diabetes mellitus. Pediatr Int. 1999;41(4):357-62.

6. Coban E, Ozdogan M, Timuragaoglu A. Effect of iron deficiency anemia on the levels of hemoglobin A1c in nondiabetic patients. Acta Haematol. 2004;112(3):126-8.

7. El-Agouza I, Abu Shahla A, Sirdah M. The effect of iron deficiency anaemia on the levels of haemoglobin subtypes: possible consequences for clinical diagnosis. Clin Lab Haematol. 2002;24(5):285-9.

8. Hardikar PS, Joshi SM, Bhat DS, Raut DA, Katre PA, Lubree $\mathrm{HG}$, et al. Spuriously high prevalence of prediabetes diagnosed by $\mathrm{HbA}(1 \mathrm{c})$ in young Indians partly explained by hematological factors and iron deficiency anemia. Diabetes Care. 2012;35(4):797-802.

9. Son JI, Rhee SY, Woo JT, Hwang JK, Chin SO, Chon $S$, et al. Hemoglobin a1c may be an inadequate diagnostic tool for diabetes mellitus in anemic subjects. Diabetes Metab J. 2013;37(5):343-8.

10. Shanthi B, Revathy C, Manjula-Devi AJS. Effect of iron deficiency on glycation of haemoglobin in nondiabetics. J Clin Diagn Res. 2013;7(1):15-7.

11. Hashimoto K, Koga M. Indicators of glycemic control in patients with gestational diabetes mellitus and pregnant women with diabetes mellitus. World J Diabetes. 2015;6(8):1045-56.

12. Mehta CR, Pocock SJ. Adaptive increase in sample size when interim results are promising: a practical guide with examples. Stat Med. 2011;30(28):3267-84.

13. Andrews NC. Disorders of iron metabolism. N Engl J Med. 1999;341(26):1986-95.

14. Baker JF, Ghio AJ. Iron homoeostasis in rheumatic disease. Rheumatology (Oxford). 2009;48(11):1339-44.

15. Datz C, Felder TK, Niederseer D, Aigner E. Iron homeostasis in the metabolic syndrome. Eur J Clin Invest. 2013;43(2):215-24.

16. Ponikowska B, Suchocki T, Paleczny B, Olesinska M, Powierza S, Borodulin-Nadzieja L, et al. Iron status and survival in diabetic patients with coronary artery disease. Diabetes Care. 2013;36(12):4147-56.

17. Gkamprela E, Deutsch M, Pectasides D. Iron deficiency anemia in chronic liver disease: etiopathogenesis, diagnosis and treatment. Ann Gastroenterol. 2017;30(4):405-13.

18. Soliman AT, De Sanctis V, Yassin M, Soliman N. Iron deficiency anemia and glucose metabolism. Acta Biomed. 2017;88(1):112-8.

19. Shimodaira M, Okaniwa S, Nakayama T. Investigation of the relationship between hemoglobin and serum iron levels and early-phase insulin secretion in non-diabetic subjects. Acta Diabetol. 2016;53(5):783-9.

20. Wheeler E, Leong A, Liu CT, Hivert MF, Strawbridge $\mathrm{RJ}$, Podmore $\mathrm{C}$, et al. Impact of common genetic 
determinants of hemoglobin A1c on type 2 diabetes risk and diagnosis in ancestrally diverse populations: a transethnic genome-wide meta-analysis. PLoS Med. 2017;14(9):e1002383.

21. Silva JF, Pimentel AL, Camargo JL. Effect of iron deficiency anaemia on HbA1c levels is dependent on the degree of anaemia. Clin Biochem. 2016;49(1-2):117-20.

22. Ng JM, Cooke M, Bhandari S, Atkin SL, Kilpatrick ES. The effect of iron and erythropoietin treatment on the A1C of patients with diabetes and chronic kidney disease. Diabetes Care. 2010;33(11):2310-3.

23. Brooks AP, Metcalfe J, Day JL, Edwards MS. Iron deficiency and glycosylated haemoglobin A. Lancet. 1980;2(8186):141.

24. Sluiter WJ, van Essen LH, Reitsma WD, Doorenbos H. Glycosylated haemoglobin and iron deficiency. Lancet. 1980;2(8193):531-2.

25. Sinha N, Mishra TK, Singh T, Gupta N. Effect of iron deficiency anemia on hemoglobin A1c levels. Ann Lab Med. 2012;32(1):17-22.
26. Ford ES, Cowie CC, Li C, Handelsman Y, Bloomgarden ZT. Iron-deficiency anemia, non-iron-deficiency anemia and HbA1c among adults in the US. J Diabetes. 2011;3(1):67-73.

27. Kalasker V, Kodliwadmath MV, Bhat H. Effect of iron deficiency on glycosylated hemoglobin levels in non diabetic indian adults. Int J Med Health Sci. 2014;3(1):40-3.

28. English E, Idris I, Smith G, Dhatariya K, Kilpatrick ES, John WG. The effect of anaemia and abnormalities of erythrocyte indices on HbA1c analysis: a systematic review. Diabetologia. 2015;58(7):1409-21.

29. Macdougall IC, Bock AH, Carrera F, Eckardt KU, Gaillard C, Van Wyck D, et al. FIND-CKD: a randomized trial of intravenous ferric carboxymaltose versus oral iron in patients with chronic kidney disease and iron deficiency anaemia. Nephrol Dial Transplant. 2014;29(11):2075-84.

30. Davis RE, McCann VJ, Nicol DJ. Influence of iron-deficiency anaemia on the glycosylated haemoglobin level in a patient with diabetes mellitus. Med J Aust. 1983;1(1):40-1. 